05.4

\title{
Деформация памяти формы и микрорельеф поверхности монокристаллов сплавов $\mathrm{Ni}-\mathrm{Fe}-\mathrm{Ga}-\mathrm{Co}$ и $\mathrm{Cu}-\mathrm{Al}-\mathrm{Ni}$
}

\author{
() Ю.Г. Носов ${ }^{1}$, А.В. Солдатов ${ }^{1}$, В.М. Крымов ${ }^{1}$, С.А. Пульнев ${ }^{1}$, В.И. Николаев ${ }^{1,2}$ \\ ${ }^{1}$ Физико-технический институт им. А.Ф. Иофффе РАН, Санкт-Петербург, Россия \\ ${ }^{2}$ Санкт-Петербургский национальный исследовательский университет информационных технологий, механики и оптики, \\ Санкт-Петербург, Россия \\ E-mail: Yu.nosov@ mail.ioffe.ru
}

Поступило в Редакцию 7 декабря 2018г.

В окончательной редакции 7 декабря 2018г.

Принято к публикации 10 декабря 2018г.

Представлены результаты экспериментальных исследований возврата монокристаллов $\mathrm{Ni}-\mathrm{Fe}-\mathrm{Ga}-\mathrm{Co}$ и $\mathrm{Cu}-\mathrm{Al}-\mathrm{Ni}$ к исходной форме на макро- и микроуровнях после их деформирования сжатием и последующего восстановительного нагрева. Установлено, что геометрические размеры образца воспроизводятся с высокой точностью (до $20 \mu \mathrm{m}$ ). Показано, что микрорельеф, появляющийся на исходно полированной поверхности при сжатии кристалла (среднее арифметическое отклонение профиля $R_{a} \approx 0.25-0.75 \mu \mathrm{m}$ и средний шаг локальных выступов профиля $S \approx 0.027-0.11 \mathrm{~mm})$, не снимается последующим нагревом и остается при дальнейшем многократном повторении циклов деформация-восстановление.

DOI: 10.21883/PJTF.2019.05.47393.17629

Сплавы с эффектом памяти формы (ЭПФ) широко используются в современной технике и медицине [1-4]. Функциональные свойства данных материалов определяются мартенситными превращениями, которые могут быть инициированы как при тепловом воздействии, так и при действии внешних полей, например магнитного поля. Интерес вызывает не только макроскопическая деформация памяти формы объемных образцов, но и деформации на микро- и наноуровнях, что связано с развитием в последнее время в том числе и миниатюрных устройств, работа которых основана на эффекте памяти формы.

Настоящая работа затрагивает вопрос точности возврата кристалла к исходной форме на макро- и микроуровнях после его деформирования сжатием и последующего восстановительного нагрева. В качестве объекта исследования нами были выбраны монокристаллы сплавов двух типов: $\mathrm{Ni}-\mathrm{Fe}-\mathrm{Ga}-\mathrm{Co}$, характеризующийся термоупругим превращением и магнитным эффектом памяти формы [5], и $\mathrm{Cu}-\mathrm{Al}-\mathrm{Ni}$ только с термоупругим превращением [6]. Использование именно монокристаллических образцов из всего многообразия материалов с эффектом памяти формы обусловлено тем, что в силу их анизотропии возможен выбор определенных кристаллографических ориентаций, в которых можно достичь полной обратимости макроскопической деформации, в отличие от поликристаллических образцов, где отмечается и пластическая деформация.

В наших экспериментах по одноосному нагружению и последующему восстановлению деформации памяти формы при обратном мартенситном превращении мы убедились, что при многократно повторяющихся циклах точность возврата к исходной форме у монокристаллов составляет одно деление винтового микрометра, т.е. $\pm 10 \mu \mathrm{m}$. Возник вопрос о физических пределах движения масс, связанного с мартенситными превращениями. В настоящей работе мы сконцентрировались на особенностях рельефа поверхности кристаллов, где, как нам кажется, можно подойти к решению поставленной задачи. Прежде всего формирующийся рельеф поверхности позволяет наблюдать перестроения мартенситной структуры, которая в конечном счете и определяет общую деформацию памяти формы.

Монокристаллы обоих сплавов выращивались способом Степанова в виде цилиндрических стержней до $10 \mathrm{~mm}$ в диаметре. После роста кристаллы подвергались высокотемпературному отжигу с последующей закалкой в воду. Для исследования боковой поверхности из стержня вырезались на электроискровом станке прямоугольные образцы размером примерно $9 \times 5 \times 3.5 \mathrm{~mm}$, что наилучшим образом подходит для их испытания одноосным сжатием. Перед деформированием боковые поверхности кристалла были отполированы алмазной шкуркой и пастой зернистостью до $1 \mu \mathrm{m}$. Сжатие образцов проводилось при комнатной температуре на испытательной машине Instron 1342 со скоростью нагружения $10^{-4} \mathrm{~s}^{-1}$. Измерение высот профиля рельефа (шероховатости) боковой поверхности проводилось с помощью профилометра RT-200. Для исследования изменения размеров кристалла при прямом и обратном мартенситных превращениях и появляющегося на его поверхности тонкого рельефа проведены следующие эксперименты.

Монокристалл $\mathrm{Ni}_{49} \mathrm{Fe}_{18} \mathrm{Ga}_{27} \mathrm{Co}_{6}$ подвергался одноосному сжатию вдоль кристаллографического направления [110]. На рис. 1 представлена диаграмма сжатия кристалла до полной деформации памяти формы, которая составляла $\sim 5 \%$. 


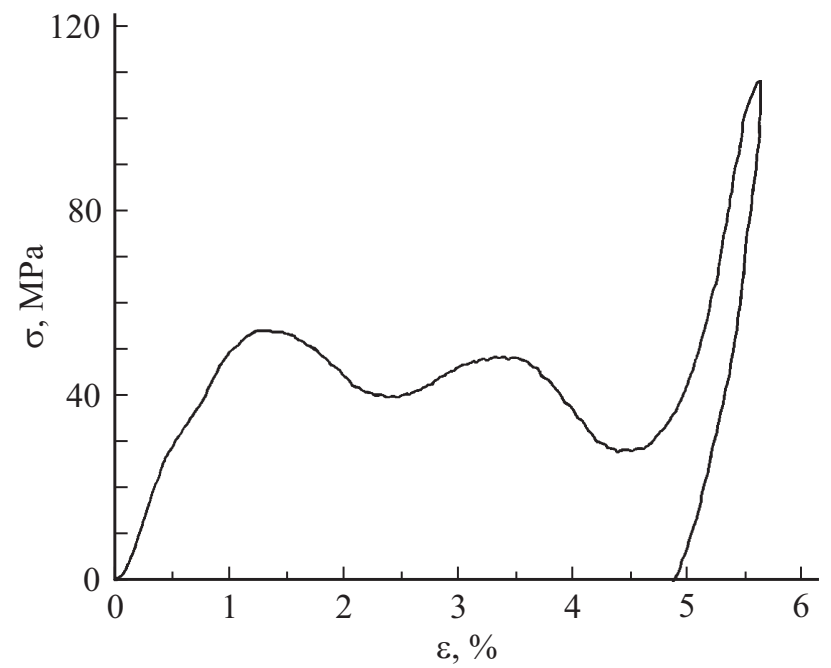

Рис. 1. Диаграмма сжатия монокристалла $\mathrm{Ni}_{49} \mathrm{Fe}_{18} \mathrm{Ga}_{27} \mathrm{Co}_{6}$ в направлении [110].

Микроскопические наблюдения показали, что после деформации на боковых поверхностях кристалла (исходно полированных) обнаруживается характерный мартенситный рельеф (рис. 2, $a$ ).

Сжатие образцов приводит к сдвигу температур мартенситных превращений исходных кристаллов в область более высоких температур, и при полной деформации памяти формы смещение составляет около $60 \mathrm{~K}$. При нагревании до температуры обратного мартенситного превращения $A_{f} \sim 383 \mathrm{~K}$ наблюдалось почти мгновенное высокоскоростное восстановление деформации памяти формы. В случае размещения кристалла на жесткой опоре превращение сопровождалось прыжком образца с начальной скоростью более $20 \mathrm{~m} / \mathrm{s}$, как это описано в работах $[7,8]$. Измерение геометрических размеров кристалла после прыжка показало, что размеры восстанавливаются до исходных, причем с высокой точностью (не хуже $\sim 20 \mu \mathrm{m})$. При этом тонкий поверхностный рельеф боковых граней не исчезал и грани к первоначальному полированному виду не возвращались, как видно из рис. 2, $b$, где представлена фотография рельефа одной из боковых граней после восстановления. Этот рельеф очень близок к рельефу, образовавшемуся на данной грани после сжатия образца (рис. 2,a), однако более детальное рассмотрение позволяет выявить бо́льшую фрагментированность рельефа.

Если поверхностный рельеф, образовавшийся при механическом сжатии кристалла, сполировывался и такой образец нагревался до восстановления деформации памяти формы, то на полированной поверхности опять появлялся тонкий рельеф (рис. 2, c), близкий к рельефу, наблюдавшемуся после деформирования (рис. 2,a). Сравнение этих структурных фотографий хотя и показывает их близость, но демонстрирует и различие. Заметим, что при фотосъемках соблюдалась строгая одинаковость освещения объекта. На вставках к рис. 2, $a$ и $c$ приведены фотографии микрорельефа, сделанные при большем увеличении одного и того же участка поверхности. Видно, что в обоих случаях картины идентичны по очертаниям рисунка, но выглядят как позитив и негатив. Это может быть объяснено тем, что выступу на рельефе поверхности, возникшему при сжатии образцов, инициирующем деформационный мартенсит, соответствует впадина на рельефе при обратном мартенситном превращении.

На рис. 3 в качестве примера представлены результаты измерения высот профиля рельефа поверхности кристалла $\mathrm{Ni}_{49} \mathrm{Fe}_{18} \mathrm{Ga}_{27} \mathrm{Co}_{6}$, показанной на рис. 2, $b$. Видно, что на поверхности присутствуют участки рельефа, различные как по высоте выступов, так и по частоте их повторяемости. Для шести различных участков с базовой длиной 0.8-1.6 mm измерены среднее арифметическое отклонение профиля $R_{a}$, наибольшая высота профиля $R_{\max }$ и средний шаг локальных выступов профиля $S$.

Выступы на поверхности в нашем случае имеют правильную симметричную форму. Можно предположить, что природа их связана с гранями мартенситных кристаллов. Для всех шести участков результаты измерений находятся в следующих пределах: $R_{a} \approx 0.25-0.75 \mu \mathrm{m}$, $R_{\max } \approx 1.7-3.9 \mu \mathrm{m} \quad$ и $S \approx 0.027-0.11 \mathrm{~mm}$. Аналогич-

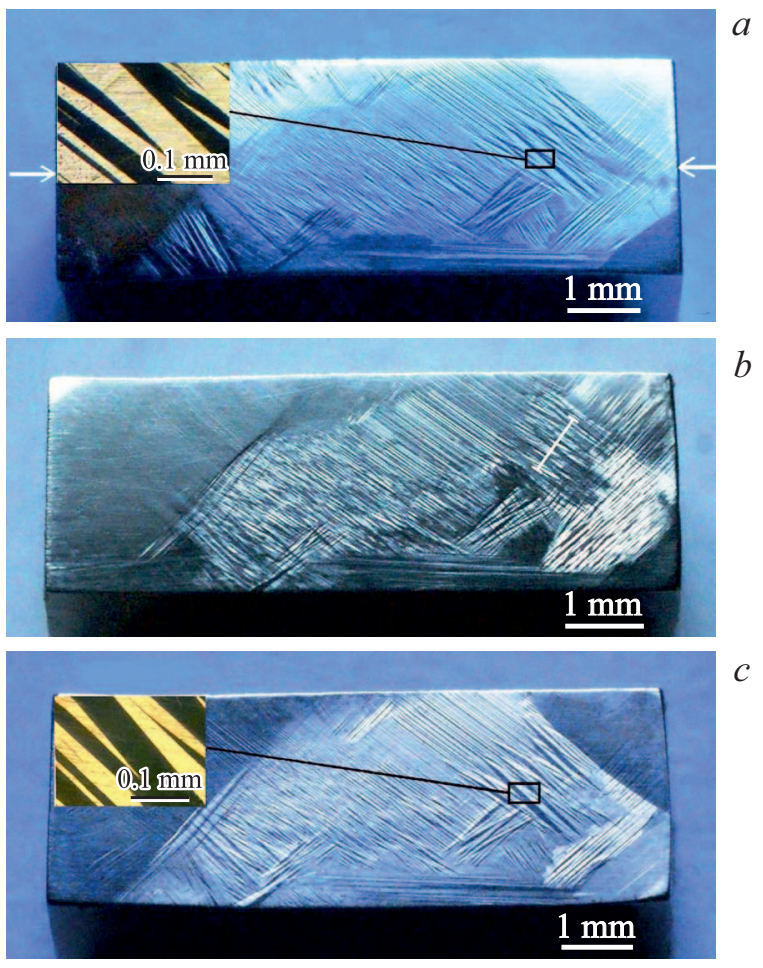

Рис. 2. Поверхностный рельеф на исходно полированной грани кристалла, появившийся в результате механического сжатия образца $(a)$, восстановления деформации нагревом $(b)$, восстановления деформации нагревом, которому предшествовала полировка рельефа, индуцированного сжатием (т.е. рельеф, показанный на части $a$, был сполирован) (c). На вставках на частях $a$ и $c$ представлен рельеф одного и того же участка поверхности при большем увеличении. Стрелками указано направление сжатия. 


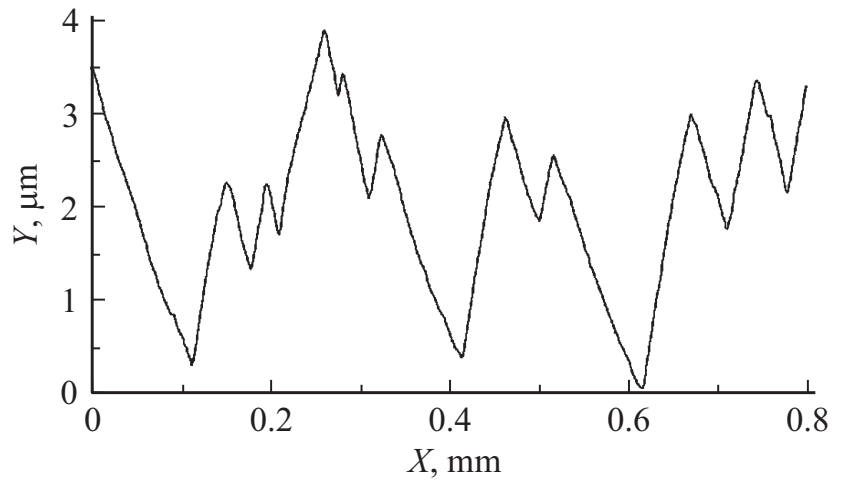

Рис. 3. Профиль высот шероховатостей, полученный на базовой длине $0.8 \mathrm{~mm}$. Путь движения иглы профилометра показан на рис. $2, b$.

ный результат был получен на монокристаллах сплава $\mathrm{Cu}-13.0$ wt.\% $\mathrm{Al}-4$ wt.\% Ni.

Мартенситный рельеф в монокристаллах с ЭПФ, описываемый выше, наблюдался ранее в сталях при их закалке. В работе [9] стальная пластинка $\mathrm{Fe}-\mathrm{Ni}-\mathrm{C} \mathrm{c}$ исходной аустенитной структурой охлаждалась (путем закалки), и при таком прямом мартенситном превращении на ней появлялся характерный поверхностный рельеф, так же как в наших опытах на сплавах с ЭПФ. Если этот рельеф сполировать, то при обратном мартенситном превращении образца (путем быстрого нагрева) вновь появился рельеф, подобный первоначальному. С одним отличием - на местах выпуклостей первого рельефа у второго имелись впадины, и наоборот. Основная причина появления поверхностного рельефа при мартенситном превращении состоит в том, что удельный объем мартенсита больше удельного объема аустенита. Как мы убедились, подобные эффекты при термоциклировании в полной степени проявляются и в наших монокристаллах.

В опытах, проведенных нами на монокристаллах с ЭПФ, появление аналогичного мартенситного рельефа вызывается деформацией образца - сжатием. Заметим, что введенный деформацией мартенсит приводит к появлению поверхностного рельефа, который при последующих циклах обратимой деформации памяти формы не исчезает и проявляется в первом же цикле, даже если исходный рельеф был убран полировкой.

Наблюдаемый нами эффект обратимости картины поверхностного рельефа при прямом и обратном мартенситных превращениях свидетельствует о том, что при изучаемых фазовых превращениях движение мартенситных границ (двойников) в кристаллической решетке может происходить по одним и тем же путям.

Таким образом, показано, что при мартенситных превращениях в монокристаллах сплавов с ЭПФ наблюдаются прямой и обратный поверхностные рельефы. Для данных кристаллов после деформации сжатием и ее восстановления нагревом геометрические размеры об- разца воспроизводятся с высокой точностью (до $20 \mu \mathrm{m}$ ). Микрорельеф, появляющийся на исходно полированной поверхности при сжатии кристалла $\left(R_{a} \approx 0.25-0.75 \mu \mathrm{m}\right.$ и $S \approx 0.027-0.11 \mathrm{~mm})$, не снимается последующим нагревом и остается при дальнейшем многократном повторении циклов деформация-восстановление, т.е. на таком уровне микрорельефа нет абсолютной воспроизводимости формы образца при мартенситных превращениях.

Авторы выражают благодарность Ю.А. Фадину за помощь в измерениях шероховатостей поверхности.

Работа выполнена в рамках госзадания № 3.1421.2017/4.6.

\section{Список литературы}

[1] Shape memory materials / Eds K. Otsuka, C.M. Wayman. Cambridge: Cambridge University Press, 1998. 284 p.

[2] Barbarino S., Saavedra Flores E.I., Ajaj R.M., Dayyani I., Friswell M.I. // Smart Mater. Struct. 2014. V. 23. P. 063001 (1-19).

[3] Mohd Jani J., Leary M., Subic A., Gibson M.A. // Mater. Design. 2014. V. 56. P. 1078-1113.

[4] Patil D., Song G. // Smart Mater. Struct. 2017. V. 26. P. 093002 (1-17).

[5] Morito H., Fujita A., Oikawa K., Ishida K., Fukamichi K., Kainuma R. // Appl. Phys. Lett. 2007. V. 90. P. 062505.

[6] Николаев В.И., Якушев П.Н., Малыгин Г.А., Аверкин А.И., Чикиряка А.В., Пульнев С.А. // Письма в ЖТФ. 2014. Т. 40. B. 3. C. $57-63$.

[7] Николаев В.И., Якушев П.Н., Малыгин Г.А., Пульнев С.А. // Письма в ЖТФ. 2010. Т. 36. В. 19. С. 83-90.

[8] Николаев В.И., Якушев П.Н., Малыгин Г.А., Аверкин А.И., Пульнев С.А., Зограф Г.П., Кустов С.Б., Чумляков Ю.И. // Письма в ЖТФ. 2016. Т. 42. В. 8. С. 18-27.

[9] Головчинер Я.М. О некоторых особенностях обратного мартенситного превращения // Сб. трудов. Проблемы металловедения и физики металлов. М: Металлургиздат, 1962. B. 7. C. $281-306$. 